Acta Technologica Agriculturae 1

Nitra, Slovaca Universitas Agriculturae Nitriae, 2016, pp. 6-9

\title{
DYNAMIC VISCOSITY AND ACTIVATION ENERGY OF WORT DURING FERMENTATION AND STORING
}

\author{
Peter HLAVÁČ ${ }^{*}$, Monika BOŽIKOVÁ, Vladimír CVIKLOVIČ \\ Slovak University of Agriculture in Nitra, Slovak Republic
}

\begin{abstract}
This paper presents the results of wort dynamic viscosity and activation energy during fermentation. The effect of temperature and storing time on both parameters was investigated. Measurements were performed on two wort samples. The first sample was taken at the beginning of fermentation, and the second sample after three hours of fermentation. Both samples were also measured after three weeks of storing. Dynamic viscosity measurements were performed with a digital rotational viscometer Anton Paar DV-3P, the principle of which is based on the dependency of sample resistance to probe rotation. Results of measurements are shown as graphical dependencies of both analysed parameters on temperature. The temperature dependence of dynamic viscosity can be characterised by a decreasing exponential function, while in case of activation energy linear increasing characters were obtained. Longer fermentation and storing period caused a decrease in both analysed parameters, due to the structural changes in wort samples during fermentation and storing.
\end{abstract}

Keywords: wort; temperature; storing time; dynamic viscosity; activation energy

For quality evaluation of food materials, it is important to identify their physical properties. During the processing of food materials, we need to check their status step by step, in different parts of processing. For detection of food material status, we could analyse chemical and physical properties. Chemical analyses usually take a longer time intervals than the study of physical properties. In modern physical research, there are often used dynamic methods of measurements, which are quicker than static methods. By using dynamic methods we can get characteristics of material in a short time (Božiková and Hlaváč, 2010).

This article deals with rheological properties, which are very complicated characteristics of materials. Results are presented as temperature relations of dynamic viscosity and activation energy in an approximate temperature range from $7{ }^{\circ} \mathrm{C}$ to $30^{\circ} \mathrm{C}$ in Figs $1-8$. The coefficients of regression equations and coefficients of determination are summarised in Table 1.

Chemical properties of wort are published by many authors, but its physical properties are almost impossible to find. Some physical properties of beer are mentioned only. Edney et al. (2007) stated that high viscosity and other factors can affect the fermentability of wort. They also found that the dynamic viscosity values of malt wort samples were in the range $(1.42-2.01) \mathrm{mPa} \cdot \mathrm{s}$ at $15^{\circ} \mathrm{C}$. Hübner et al. (2010) investigated the influence of germination time and temperature on the properties of rye malt and rye malt based worts. They found out that the dynamic viscosity of rye malt based worts had higher values than barley malt based worts. Monošík et al. (2013) monitored the amounts of sugar levels and alcohols during wort fermentation. The authors proved that the amount of sugars is decreasing during fermentation, while the amount of alcohol is increasing.
Ganatsios et al. (2014) described the advantages of maltose fermentation at low temperatures using a special type of yeasts. The authors also determined the activation energy of maltose fermentation by yeasts cell free and immobilised. The influence of aging or storing of beer was examined by many authors (Vanderhaegen et al., 2006; Caballero et al., 2012; Nimubona et al., 2013; etc.).

Viscosity as one of the most important rheological parameters is defined as the resistance of a fluid to flow. The unit of dynamic viscosity in SI units is Pa.s. Viscosity changes with temperature. The difference in the effect of temperature on the viscosity of fluids and gases is related to the difference in their molecular structure. The viscosity of most of the liquids decreases with increasing temperature. Theories have been proposed regarding the effect of temperature on the viscosity of liquids. According to Eyering theory, molecules of liquids continuously move into the vacancies (Bird et al., 2002). This process permits flow but requires energy. The temperature effect on viscosity can be described by an Arrhenius type equation:

$$
\eta=\eta_{0} e^{-\frac{E_{A}}{R T}}
$$

where:

$$
\begin{array}{ll}
\eta_{0} & - \text { the reference value of dynamic viscosity } \\
E_{A} & - \text { activation energy } \\
R & - \text { gas constant } \\
T & - \text { absolute temperature (Figura and Teixeira, 2007). }
\end{array}
$$

Activation energy is more readily audible at higher temperatures, and the fluid flows easily. In chemistry, activation energy means the amount of energy that is required to activate atoms or molecules to a condition in 
which they can undergo chemical transformation or physical transport. In terms of the transition-state theory, activation energy is the difference in energy content between atoms or molecules in an activated or transition-state configuration and the corresponding atoms and molecules in their initial configuration. Activation energies are determined experimentally at different temperatures (Mansur et al., 2014). Liquid molecules are closely spaced with strong cohesive forces between them. The temperature dependence of viscosity can also be explained by cohesive forces between molecules (Munson et al., 1994). As temperature increases, these cohesive forces between molecules decrease and flow becomes freer. As a result viscosities of liquids decrease as temperature increases. In liquids, the intermolecular (cohesive) forces play an important role. Viscosities of liquids show little dependence on density, molecular velocity or mean free path. In most liquids, viscosity is constant up to a pressure $10.134 \mathrm{MPa}$, but at higher pressures viscosity increases as pressure increases (Sahin and Sumnu, 2006).

\section{Material and methods}

Wort is the liquid extracted from the mashing process during the brewing of beer or whisky. Sugars contained in wort are changed to alcohol by the brewing yeasts during fermentation. In our research, we analysed two wort samples. The first sample was taken at the beginning of fermentation, and the second sample after three hours of fermentation. Both samples were also measured after three weeks of storing. The measured samples were cooled to the temperature $5{ }^{\circ} \mathrm{C}$, and dynamic viscosity was measured in the temperature range $(7-30)^{\circ} \mathrm{C}$.

Measuring of dynamic viscosity was performed by the digital viscosimeter Anton Paar (DV-3P). Measurement is based on the dependency of sample resistance to probe rotation. Temperature dependencies of dynamic viscosity can be described by decreasing exponential functions (2):

$$
\eta=A e^{-B\left(\frac{t}{t_{0}}\right)}
$$

In our case, temperature dependencies of activation energy can be described by a linear increasing function (3):

$$
E_{A}=C\left(\frac{t}{t_{0}}\right)-D
$$

where:

$$
\begin{aligned}
& t \quad-\text { temperature } \\
& t_{0}-1^{\circ} \mathrm{C}
\end{aligned}
$$

$A, B, C, D$ - constants dependent on the kind of material and on ways of processing and storing

\section{Results and discussion}

Temperature dependencies of dynamic viscosity for both wort samples without storing and after three weeks of storing are shown in Figs 1 and 2. The coefficients of regression equations and coefficients of determination are summarised in Table 1.
It is possible to observe from Figure 1 and Figure 2 that the dynamic viscosity of worts is decreasing with increasing of temperature. The progress can be described by a decreasing exponential function, which is in accordance with Arrhenius equation (1). The regression coefficients and coefficients of determination are shown in Table 1. It can be seen from Figure 1 that the dynamic viscosity of the second sample of wort (after three hours of fermentation) is lower than for the first sample (without fermentation). Same position of curves, but with bigger difference, can be seen in Figure 2 after three weeks of storing. This was caused by structural changes in wort during fermentation and storing.

It can be seen in Figure 3 and Figure 4 that storing caused a decrease of dynamic viscosity for both samples. This could be also interpreted by structural changes during fermentation and storage.

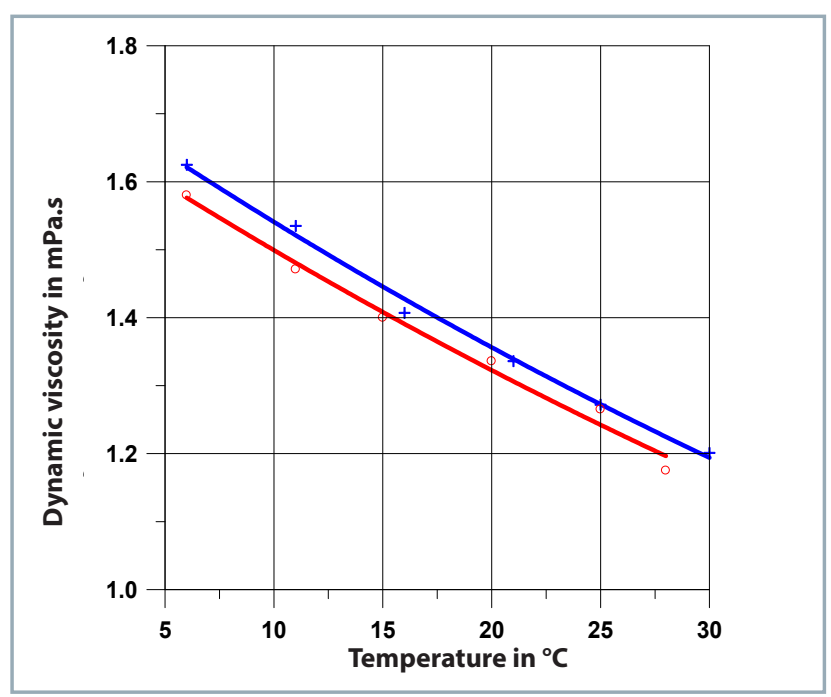

Figure 1 Temperature dependencies of wort dynamic viscosity for samples without storing (at beginning of fermentation + , after $3 \mathrm{~h}$ of fermentation o)

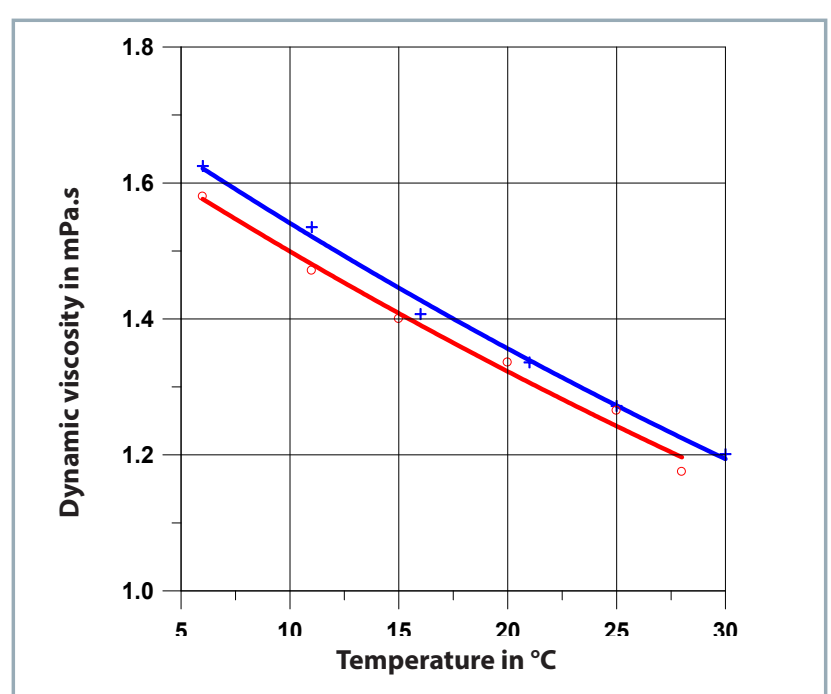

Figure 2 Temperature dependencies of wort dynamic viscosity for samples after three weeks of storing (at beginning of fermentation + , after $3 \mathrm{~h}$ of fermentation o) 
Table 1 Coefficients $A, B, C, D$ of regression equations $(2,3)$ and coefficients of determinations $\left(R^{2}\right)$

\begin{tabular}{|c|c|c|c|}
\hline \multirow[b]{3}{*}{ Sample / Storing } & \multicolumn{3}{|c|}{ Regression equations $(2,3)$} \\
\hline & \multicolumn{3}{|c|}{ Coefficients } \\
\hline & $A$ in $\mathrm{mPa} . \mathrm{s}$ & $B[1]$ & $R^{2}$ \\
\hline First / $0 \mathrm{~h}$ & 1.75034 & 0.0127518 & 0.994918 \\
\hline Second / $0 \mathrm{~h}$ & 1.69938 & 0.0125308 & 0.985131 \\
\hline First / 3 weeks & 1.69644 & 0.0129946 & 0.992997 \\
\hline Second / 3 weeks & 1.56049 & 0.0117605 & 0.993794 \\
\hline Sample / Storing & $C$ in $\mathrm{J} \mathrm{mol}^{-1}$ & $D$ in $\mathrm{J} \mathrm{mol}^{-1}$ & $R^{2}$ \\
\hline First / $\mathbf{O h}$ & 32.7627 & 27.0674 & 0.99948 \\
\hline Second / $0 \mathrm{~h}$ & 32.04 & 24.6581 & 0.99959 \\
\hline First / 3 weeks & 33.1837 & 28.9552 & 0.99983 \\
\hline Second / 3 weeks & 29.8155 & 21.9441 & 0.999768 \\
\hline
\end{tabular}

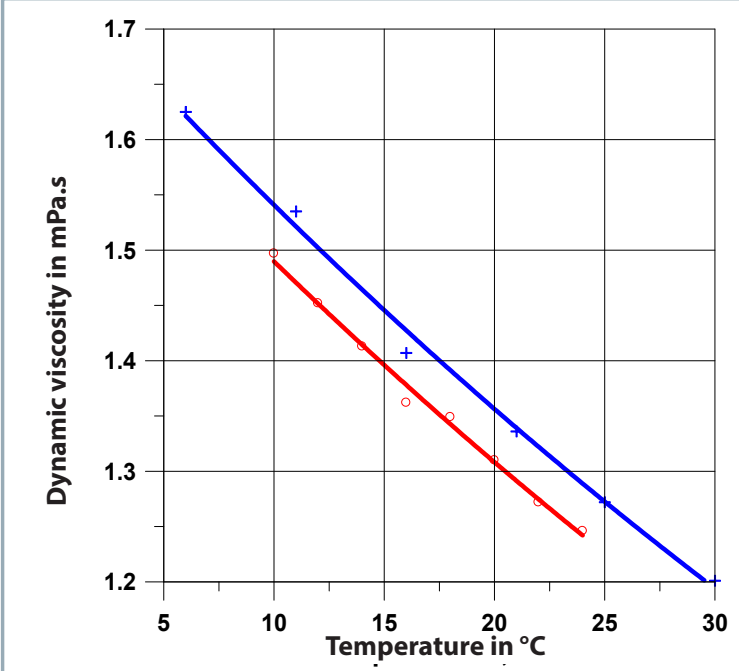

Figure 3 Temperature dependencies of wort dynamic viscosity (first sample without fermentation) (without storing + , after 3 weeks of storing o)

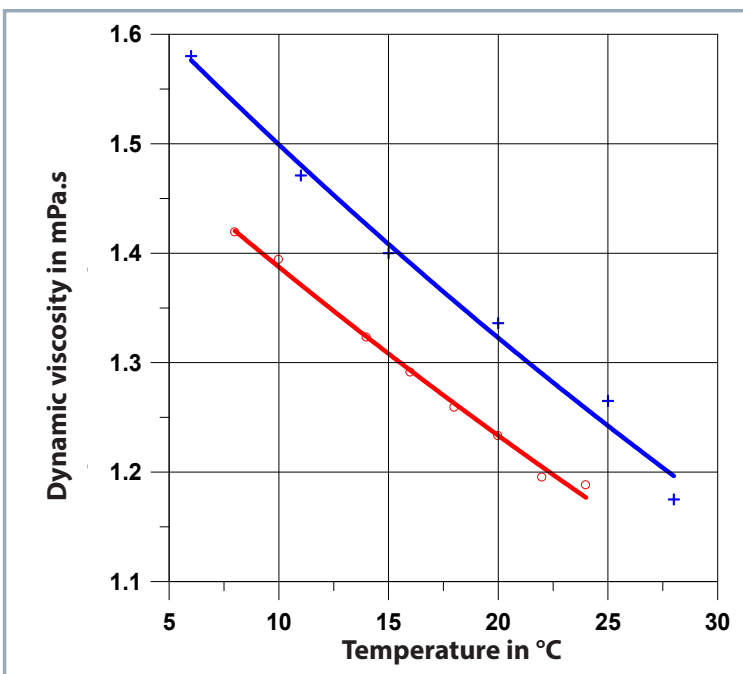

Figure 4 Temperature dependencies of wort dynamic viscosity (second sample after three hours of fermentation) (without storing + , after 3 weeks of storing o)

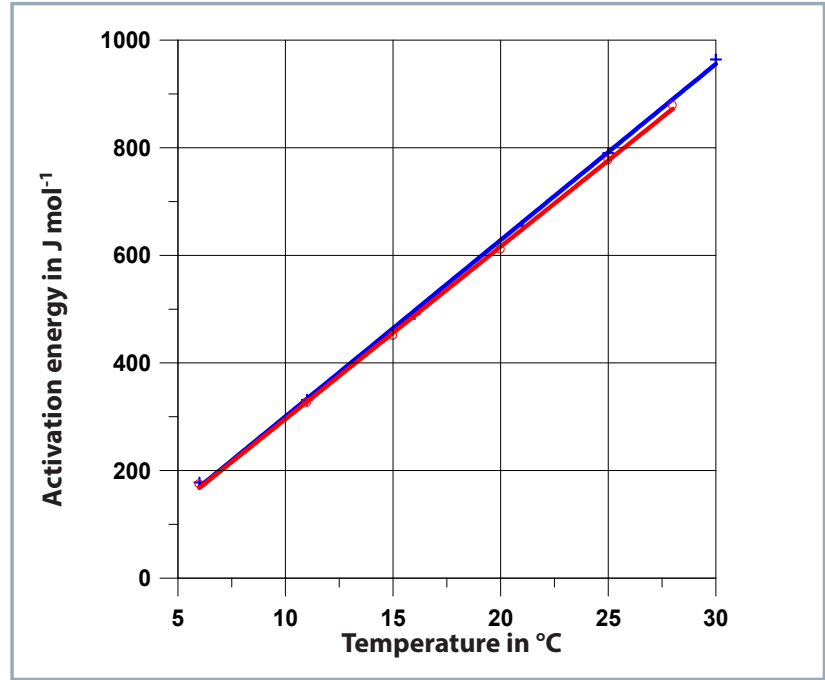

Figure 5 Temperature dependencies of wort activation energy for samples without storing (at beginning of fermentation + , after $3 \mathrm{~h}$ of fermentation $\mathrm{o}$ )

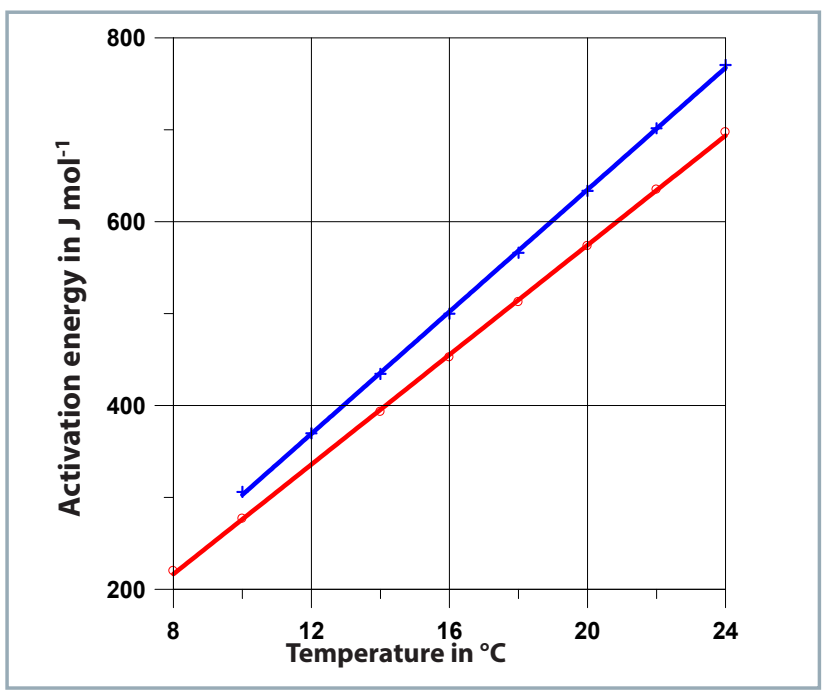

Figure 6 Temperature dependencies of wort activation energy for samples after three weeks of storing (at beginning of fermentation + , after $3 \mathrm{~h}$ of fermentation o)

In case that $\eta_{0}=A$, Eq. 1 and Eq. 2 can be used for calculation of activation energy at different temperatures. Dependencies of activation energy on temperature are shown in Figs 5-8 and in this case these dependencies had an increasing linear character. The coefficients of regression equations and coefficients of determination are summarised in Table 1.

It can be seen in Figure 5 and Figure 6 that activation energy decreased a bit after fermentation. It is more visible on stored sample (Figure 6). On the other hand, values of activation energy almost did not change for the first sample without fermentation (Figure 7). Values of activation energy were a bit lower after storing for the second fermented sample (Figure 8).

It can be seen in Table 1 that the coefficients of determination are very high in all measurements, not lower than 0.985 . 


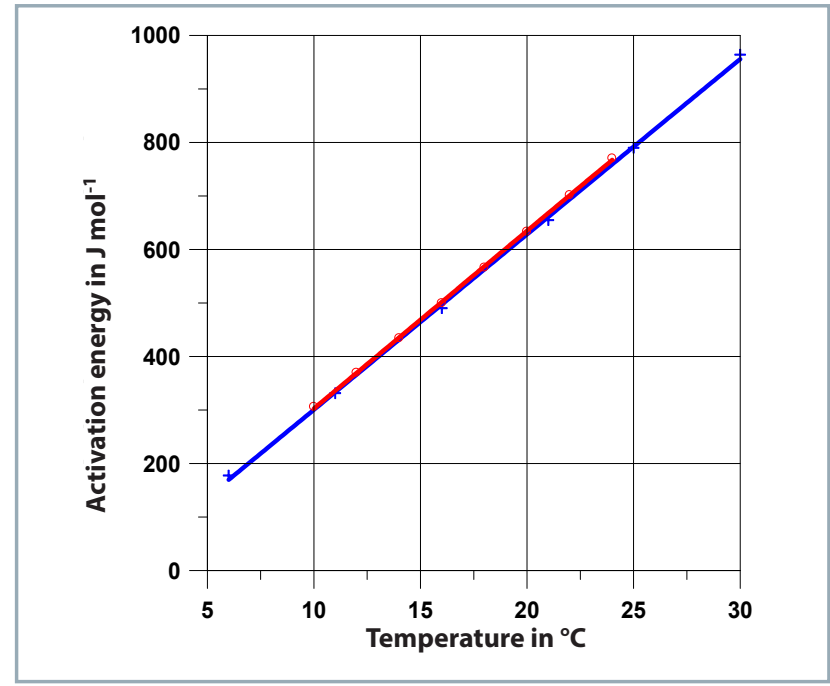

Figure 7 Temperature dependencies of wort activation energy (first sample without fermentation) (without storing + , after 3 weeks of storing o)

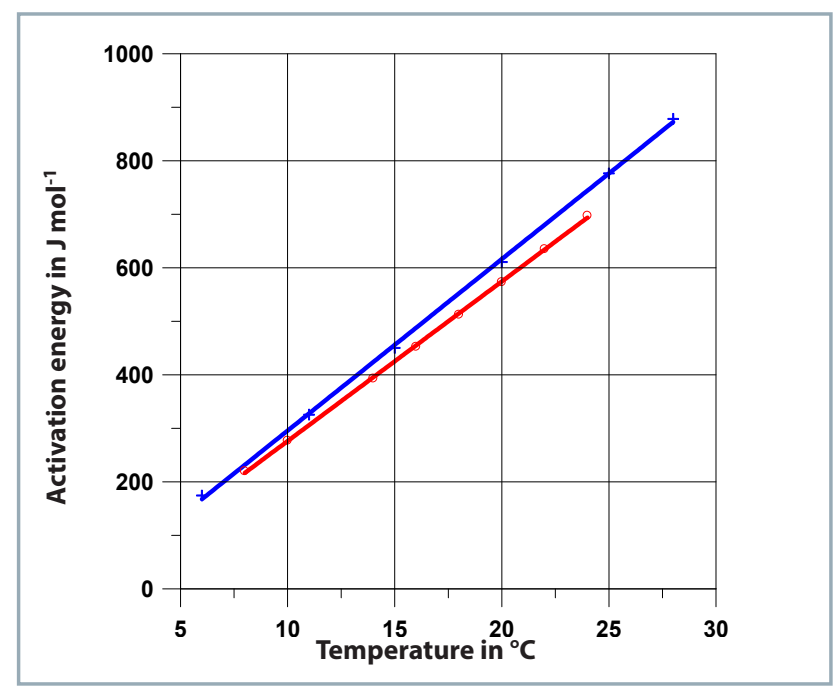

Figure 8 Temperature dependencies of wort activation energy (second sample after three hours fermentation) (without storing + , after 3 weeks of storing 0 )

\section{Conclusion}

Many raw materials for foods and many finished foods are in the form of fluids. These fluids have to be transported and processed in the factory. Food technologists must be familiar with the principles that govern the flow of fluids, and with the machinery and equipment that is used to handle fluids (Datta, 2012). Automatically controlled processes at manufacturing, at handling and holding require exact knowledge about physical quantities of materials. For quality evaluation of food materials, it is necessary to know their physical parameters, for example rheological properties (Božiková and Hlaváč, 2010). The rheological properties and ways of their usage in flowing processes of food fluids are described, e.g. by Rao et al. (2005).

Temperature dependencies of wort samples dynamic viscosity had an exponential decreasing shape, which is in accordance with Arrhenius equation (1). We found out that values of dynamic viscosity were lower after fermentation and storing (Figs 1-4), due to the structural changes in wort during fermentation and storing. Obtained results of dynamic viscosity are comparable with values presented by Edney et al. (2007). The linear increasing progress can be observed at temperature dependencies of activation energy (Figs 5-8). Activation energy was affected by fermentation and storing in the same way as dynamic viscosity. This could be also caused by structural changes in wort during fermentation and storing. It can be seen that fermentation and storing have an influence on both analysed parameters: dynamic viscosity and activation energy.

\section{References}

BIRD, R. B. - STEWART, W. E. - LIHGTFOOT, E. N. 2002. Transport Phenomena. New York : John Wilie \& Sons, 2002. 895 pp.

CABALLERO, I. - BLANCO, C. A. - PORRAS, M. 2012. Iso-a-acids, bitterness and loss of beer quality during storage. In Trends in Food Science and Technology, vol. 26, 2010, pp. 21-30.

BOŽIKOVÁ, M. - HLAVÁČ, P. 2010. Selected Physical Properties of Agricultural and Food Products. (Scientific monograph). Nitra : SUA, 2010. 178 pp. ISBN 978-80-552-0428-4.

DATTA, A. K. 2012. Fluid - flow Theory (Chapter 3). India : VTU Centre Mysuru, 2012. pp. 1-27.

EDNEY, M. J. - EGLINTON, J. K. - COLLINS, H. M. - BARR, A. R. LEGGE, W. G. - ROSSNAGEL, B. G. 2007. Importance of endosperm modification for malt wort fermentability. In Journal of the Institute of Brewing, vol. 113, 2007, no. 2, pp. 228-238.

FIGURA, L. O. - TEIXEIRA, A. A. 2007. Food Physics, Physical properties - Measurement and Applications. USA : Springer, 2007. $550 \mathrm{pp}$.

GANATSIOS, V. - KOUTINAS, A. A. - BEKATOROU, A. - KANELLAKI, M. - NIGAM, P. 2014. Promotion of maltose fermentation at extremely low temperatures using a cryotolerant Saccharomyces cerevisiae strain immobilized on porous cellulosic material. In Enzyme and Microbial Technology, vol. 66, 2014, pp. 56-59.

HÜBNER, F. - SCHEHL, B. D. - GEBRUERS, K. - COURTIN, CH. M. DELCOUR, J. A. - ARENDT, E. K. 2010. Influence of germination time and temperature on the properties of rye malt and rye malt based worts. In Journal of Cereal Science, vol. 52, 2010, pp. 72-79.

MANSUR G. A. et al. 2014. Encyclopaedia Britannica. Available at: http://www.britannica.com/EBchecked/topic/4535/activation -energy

MONOŠÍK, R. - MAGDOLEN, P. - STREĎANSKÝ, M. - ŠTURDÍK, E. 2013. Monitoring of monosaccharides, oligosaccharides, ethanol and glycerol during wort fermentation by biosensors, HPLC and spectrophotometry. In Food Chemistry, vol. 138, 2013, pp. 220-226. MUNSON, B. R. - YOUNG, D. F. - OKIISHI, T. H. 1994. Fundamentals of Fluid Mechanics. New York : John Wilie \& Sons, 1994.

NIMUBONA, D. - BLANCO, C. A. - CABALLERO, I. - ROJAS, A. ANDRÉS-IGLESIAS, C. 2013. An approximate shelf life prediction of elaborated lager beer in terms of degradation of its iso-a-acids. In Journal of Food Engineering, vol. 116, 2013, pp. 138-143.

RAO, M. A. - RIZVI, S. S. H. - DATTA, A. K. 2005. Engineering properties of foods. $3^{\text {rd }}$ ed. New York: CRC Press, 2005. 733 pp.

SAHIN, S. - SUMNU, S. G. 2006. Physical Properties of Foods. USA : Springer, 2006. 257 pp.

VANDERHAEGEN, B. - NEVEN, H. - VERACHTERT, H. - DERDELINCKX, G. 2006. The chemistry of beer aging - a critical review. In Food Chemistry, vol. 95, 2006, pp. 357-381. 